\title{
AN IMPTOVED MASS-REARING METHOD OF THE CARROT RUST FLY, PSILA ROSAE (DIPTERA: PSILIDAE)
}

\author{
E. STÄDLER
}

Swiss Federal Research Station, $\mathrm{CH}-8820$ Wädenswil, Switzerland

\begin{abstract}
Can. Ent. 103: 1033-1038 (1971)

Protein fed to adults of the carrot rust fly, Psila rosae F., enhanced oviposition: the addition of yeast hydrolysate to the sugar diet resulted in a $50 \%$ increase in oviposition, giving an average of 75 eggs per female.

A description is given of a simple oviposition device, which allows normal oviposition (compared with sand).

Carrots planted in sand gave best rearing results when inoculated with eggs 14 days after insertion. Germinating carrot seeds placed on top of the sand improved the rate of development of the eggs to pupae from $40 \%$ to $62 \%$.
\end{abstract}

\section{Introduction}

The method described for the rearing of the carrot rust fly, Psila rosae F., is based on investigations made by McClanahan and Niemczyk (1963), Naton (1966, 1968), and Bohlen (1967). The rearing was begun with flies caught outdoors in Autumn 1967 using the method from Bohlen (1967). The following investigations were carried out in order to minimise the work involved and at the same time have constant optimal conditions for rearing. The larvae and flies were used for behavioural and orientation studies.

\section{Material and Methods}

Adults. The cages used (Fig. 1) have a metal frame-work $(30 \times 30 \times 30$ $\mathrm{cm}$ ). Ceiling and sides are formed by screwing together sheet metal frames covered in brass wire netting ${ }^{1}$ (mesh $3 / 4 \mathrm{~mm}$ ). The front consists of a plexiglass plate with three openings. A large opening, over which a bottomless plastic beaker is glued, acts as entrance. The beaker is separated from the cage by a plastic curtain. Dead flies can be sucked out through the two small holes in the bottom half of the front. The floor of the cage is made of galvanised sheeting and has four evenly spaced openings (ca. $10 \mathrm{~cm}$ ), each of which is covered with a black nylon net (mesh $1 \mathrm{~mm}$ ).

The flies are reared at a temperature of $21^{\circ} \pm 1^{\circ} \mathrm{C}$ and a relative humidity of $70 \pm 5 \%$ (Wakerley 1964). The cages are lighted from above for 18 hours per day using tubular lamps (Philipps TLF $20 \mathrm{~W} / 33$ ). Two yellow foam rubber mats on the ceiling of the cage produce a diffuse, even light of 100-500 lux.

A $1 \%$ water-agar mixture in a yoghurt beaker turned upside down on top of the cage (Fig. 1) provides the necessary water (method of Peleg and Rhode, 1967). The diet consists of 4 parts cane sugar : 1 part enzymatic yeast hydrolysate ${ }^{8}: 1 \frac{1}{1 / 2}$ parts water (Hagen and Finney 1950) and is coated on to the two foam rubber strips $15 \mathrm{~cm} \times 15 \mathrm{~cm} \times 4 \mathrm{~mm}$, which are laid on the ceiling. The agar beaker and the feeding strips must be replaced approximately every 3 weeks.

For oviposition stimulation we use well-developed carrot leafage put into a $200 \mathrm{ml}$ brown bottle (Naton 1968). The stimulated flies deposit the eggs through the four openings furnished with nylon net on to the oviposition devices, which are petri dishes (ca. $9.5 \mathrm{~cm}$ ) with a $2.5 \mathrm{~cm}$ thick wetted foam rubber lining. A black synthetic cloth is fixed over the dish with rubber bands. It is divided into $1 \mathrm{~cm}$

sNutritional Biochemicals, Cleveland, Ohio, U.S.A. 


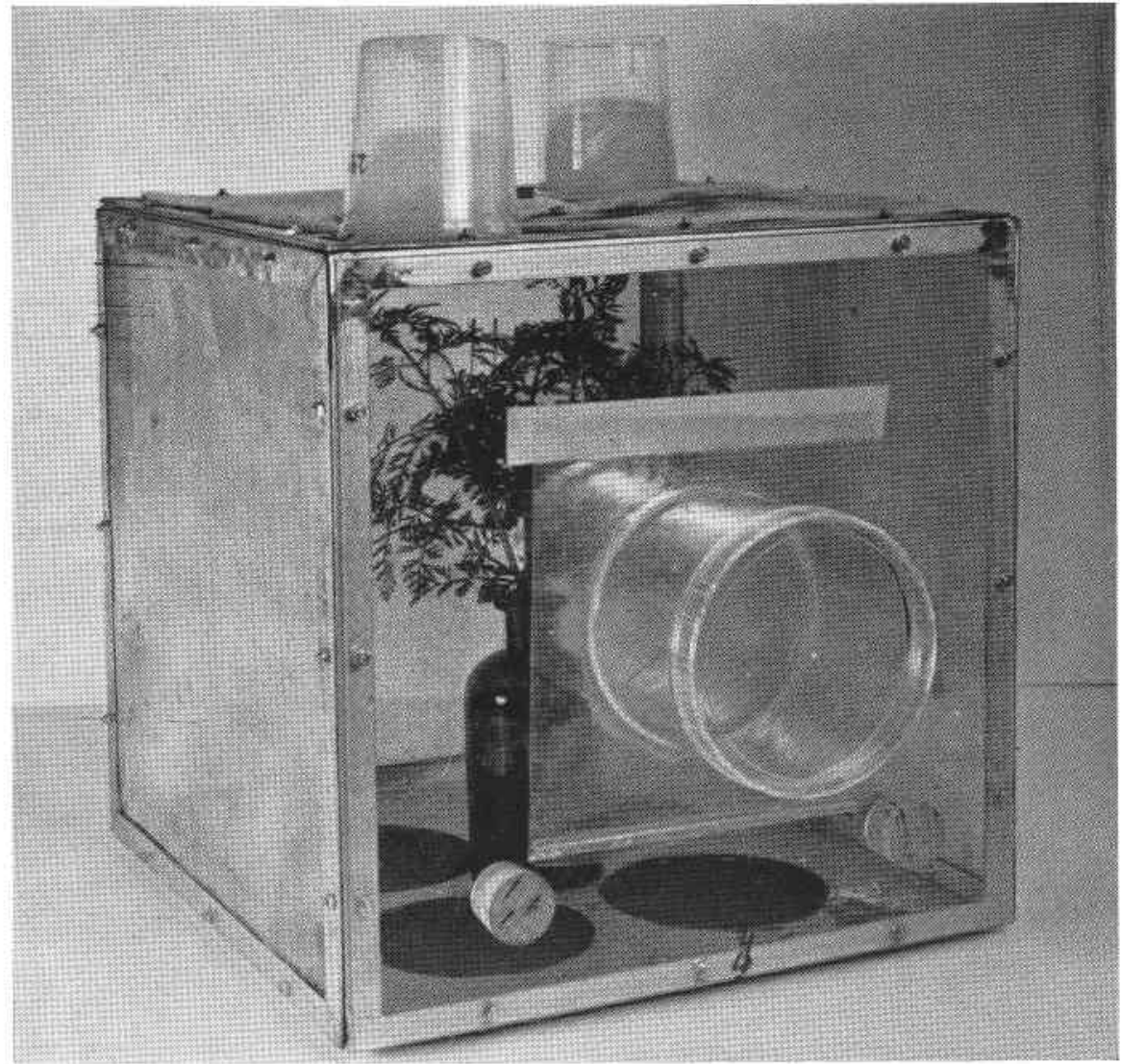

FIG. 1. Rearing cage for the flies of $P$. rosae. On the ceiling: two yoghurt beakers with water-agar providing the flies with water and two foam rubber strips coated with a mixture of cane sugar and enzymatic yeast hydrolysate $(4: 1)$ serving for nutrition. In the cage: brown bottle with inserted carrot leaves which stimulate oviposition. On the floor: four openings covered with black nylon net through which the eggs are laid.

squares with red thread in order to facilitate counting of the eggs (Fig. 2a). An additional nylon net is laid over the oviposition dishes (Fig. 2b).

The emergence of the flies from the pupae takes place in special emergence containers. These consist of bottomless yoghurt beakers glued to suitable plastic petri dishes (ca. $7 \mathrm{~cm}$ ), with a nylon gauze (mesh $200 \mu$ ) forming the bottom of the beaker where the pupae are laid. A suitable cover is placed over the beaker. The water in the petri dish ensures the $100 \%$ relative air humidity required by the pupae (Wiesmann, pers. comm., 1967).

Sex differentiation of living carrot flies is somewhat uncertain without the aid of a magnifying glass (Naton 1968). The flies are therefore anesthetised with carbon dioxide, a procedure which results in extension of the ovipositor in the female and allows a clear distinction from the male to be made. Since $\mathrm{CO}_{2}$ administered over longer periods can be harmful (Harris et al. 1965), the duration of anesthetisation is kept as short as possible.

LARvaE. For the rearing of larvae we use, like Bohlen (1967), stored carrots bedded in damp sand. In addition carrot seeds are sown in the top layer. Eternit 


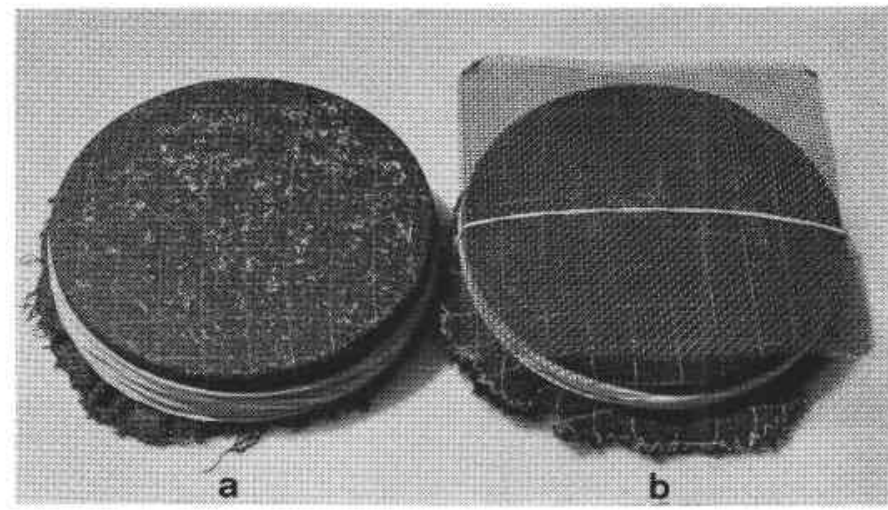

FIG. 2. Oviposition devices consisting of a petri dish with a wetted foam rubber lining, covered with black cloth. (a) Device covered with eggs. (b) Device with additional nylon net.

dishes $^{4}$ and clay pots are used for rearing experiments. Between 1 and 3 weeks after insertion of the carrots, the 1- to 4-day-old eggs are washed on to the top layer of sand, each carrot receiving up to 100 eggs.

The soil temperature in the green-house is regulated to $20^{\circ} \pm 1^{\circ} \mathrm{C}$ (Städler 1970). The trays are sprayed with water once a day so that the surface is kept damp.

Forty-two days after inoculation of the carrots with eggs the pupae can be washed out of the sand using a wash apparatus. ${ }^{5}$ From each rearing dish an average of 500-1000 pupae were obtained (maximum 2200 pupae).

\section{Results and Discussion}

Adult EMERGence Box. A comparison was made of the emergence rates of pupae from three different emergence boxes: Dishes as described by Zwölfer (1932) and the yoghurt beakers as mentioned above with and without a sand covering. An average emergence rate of $80 \%$ normal flies was obtained in a series of three experiments. There was no significant difference between the three types of container. The relatively great variation noted (69-92\%) was attributed to the varying quality of the pupae. In further experiments, the yoghurt beaker without sand as described above was employed as emergence box. For successful marking of emerging flies a cover of $40 \mathrm{~g}$ of dry sand mixed with $0.2 \mathrm{~g}$ fluorescent colour was used (Norris 1957).

Nutrition of Adults. It has long been established that sugar and water must be given to the flies if normal oviposition is to be induced (Körting 1940; Wiesmann, pers. comm., 1967). Up until now, however, there have been no investigations made into the effects and the importance of protein in the adult diet. Preliminary experiments carried out with sugar, cane sugar/yeast hydrolysate mixture, sugar/soja meal mixture, sugar/soja meal/yeast hydrolysate mixture, honey and condensed, sweetened milk showed that the most effective mixture for oviposition was the cane sugar/yeast hydrolysate mixture. Oviposition results with flies on a diet of cane sugar alone and cane-sugar with addition of yeast hydrolysate 
Table I. The effect on oviposition of enzymatic yeast hydrolysate in the adult diet

\begin{tabular}{lccccc}
\hline \hline & & & \multicolumn{2}{c}{ Eggs per female } \\
\cline { 4 - 5 } \multicolumn{1}{c}{ Diet } & $\begin{array}{c}\text { No. of } \\
\text { repetitions }\end{array}$ & $\begin{array}{c}\text { No. of } \\
\text { females }\end{array}$ & Av. & $\begin{array}{c}\text { Standard } \\
\text { deviation }\end{array}$ \\
\hline $\begin{array}{l}\text { Cane sugar } \\
\text { Cane sugar }+ \\
\text { yeast hydrolysate }(4: 1)\end{array}$ & 5 & 96 & 46.4 & 5.0 \\
\hline \hline
\end{tabular}

were then compared. The flies which received the additional yeast hydrolysate were found to deposit significantly more eggs (Table I: $P=0.01$ ).

Towards the end of the oviposition period it was observed that the females on a diet free of yeast hydrolysate deposited smaller eggs. Protein deficiency is thought to be responsible for this reduction in size. The improved oviposition results can probably be attributed to the protein and amino-acid content of the added yeast hydrolysate.

The natural source of food for the carrot rust fly is found in the blossom of wild Umbelliferae (Petherbridge et al. 1942) and in the shelter plants in the form of honey-dew (Watkins and Miner 1943). According to the investigations with fruit-flies carried out by Hagen (1958), honey-dew is an important source of carbohydrates and protein. In experiments using cabbage root flies it has also been shown by Finch and Coaker (1969) that the blossom of wild Umbelliferae is rich in carbohydrates.

Ovipositron Device. To facilitate counting in the oviposition experiments, an attempt was made to find an oviposition device having neither sand nor soil. Swailes (1967) with Hylemyia brassicae, Audemard (1967) with H. cilicrura, and Naton (1968) with Psila rosae employed artificial oviposition devices which replaced earth as the natural site. We used the modified method of Audemard (1967) as described above. The results of nine experiments showed that no difference existed between oviposition with the artificial device and with sand (Table II).

REARING of LARvae. At first, difficulties were often encountered especially in spring due to the relatively quick rotting of the carrots in sand. Our attempts to restrict the decay using various fungicides and disinfectants remained, unlike those of Schnitzler (1969) for $H$. brassicae, unsuccessful. Experiments to determine the optimal water content in the sand trays also brought no improvement. An attempt was therefore made to shorten as far as possible the period during which the carrots were in sand. Since according to various authors newly emerged larvae feed exclusively on lateral roots and only the $\mathrm{L}_{2}-\mathrm{L}_{3}$ stages make their way into the carrot itself, a certain amount of time must first be allowed for the development of lateral roots. The longer the carrots are bedded in damp sand, however, the greater the decay. The results of the experiment shown in Table III indicate that the best

Table II. Comparison of oviposition with sand trays and artificial oviposition devices

\begin{tabular}{lcc}
\hline \hline \multicolumn{1}{c}{ Oviposition medium } & No. of repetitions & Total no. of eggs deposited \\
\hline Sand & $9 \times 2$ & 4155 \\
Artificial oviposition device & $9 \times 2$ & 4127 \\
\hline
\end{tabular}


Table III. The effect on rearing results of length of time elapsing before inoculation of carrots with eggs

\begin{tabular}{cccc}
\hline $\begin{array}{c}\text { Time elapsing before } \\
\text { inoculation }\end{array}$ & $\begin{array}{c}\text { No. of eggs } \\
\text { per repetition }\end{array}$ & $\begin{array}{c}\text { No. of } \\
\text { repetitions }\end{array}$ & $\begin{array}{c}\text { Pupae } \\
\text { (av.) }\end{array}$ \\
\hline $0-4$ days & 150 & 8 & $28.5 \mathrm{a}^{*}$ \\
$7-11$ ", & 150 & 8 & $50.1 \mathrm{~b}$ \\
$14-18, "$ & 150 & 8 & $40.5 \mathrm{a}, \mathrm{b}$ \\
$21-24$, & 150 & & 47.8 \\
Total av. & & & 20.3 \\
Smallest significant diff. $P=0.05$ & & \\
\hline \hline
\end{tabular}

*Between averages marked with the same letter, no statistically significant difference was found.

rearing results are obtained 14-18 days after inserting the carrots (on the average 72 pupae developing out of 150 eggs).

If 3 weeks were allowed to elapse before inoculation, rotting of the carrots had a negative effect (lack of food for the growing larvae). Since rearing results are dependent on the development of lateral roots, an experiment was carried out making use of germinating seeds on top of the sand (Table IV). The number of pupae developing from the eggs was found to increase from $40 \%$ to $62 \%$ (statistically significant, $P=0.01$ ) by addition of germinating seeds.

The method described is both economical and practical and is therefore suitable for mass-rearing of the carrot rust fly. Provided that healthy, unwashed carrots are used, an average offspring of 40 adults can be expected from one female fly.

Table IV. Influence of germinating carrot seed on the rearing results

\begin{tabular}{lcccc}
\hline \hline & $\begin{array}{c}\text { Time elapsing } \\
\text { before inoculation }\end{array}$ & $\begin{array}{c}\text { No. of } \\
\text { eggs }\end{array}$ & $\begin{array}{c}\text { No. of } \\
\text { repetitions }\end{array}$ & $\begin{array}{c}\text { Pupae } \\
\text { (av.) }\end{array}$ \\
\hline $\begin{array}{l}\text { Carrots without seeds } \\
\text { Carrots with 200 seeds }\end{array}$ & $7-10$ days & 200 & 8 & 79.5 \\
at the surface & $7-10$ days & 200 & 6 & 124.2 \\
\hline \hline
\end{tabular}

\section{Acknowledgments}

The writer wishes to express his appreciation to Dr. J. Klingler, Swiss Federal Research Station, Wädenswil, and Dr. J. F. Doane, Canada Agriculture Research Station, Saskatoon, for their interest and help in the preparation of the manuscript; and to Mrs. Beriiter for translation.

\section{References}

Audemard, H. 1967. L'élevage permanent de la mouche des semis Phorbia platura Meigen (Hylemyia cilicrura Rondani) Diptera Muscidae. Annls Épiphyt. 18: 551-555.

Bohlen, E. 1967. Untersuchungen zum Verhalten der Möhrenfliege, Psila rosae Fab. (Dipt. Psilidae) im Eiablagefunktionskreis. Z. angew. Ent. 59: 325-360.

Finch, S. and T. H. Coaker. 1969. Comparison of the nutritive values of carbohydrates and related compounds to Erioischia brassicae. Ent. exp. appl. 12: 441-453.

Hagen, K. S. 1958. Honeydew as an adult fruit fly diet affecting reproduction. Proc, 10th int. Congr. Ent. (1956), Vol. 3, pp. 25-30.

Hagen, K. S. and G. L. Finney. 1950. A food supplement for effectively increasing the fecundity of certain tephritid species. J. econ. Ent. 43: 735.

Harris, R. L., R. A. Hoffman, and E. D. Frazar. 1965. Chilling vs. other methods of immobilizing flies. J. econ. Ent. 58: 379-380. 
Körting, A. 1940. Zur Biologie und Bekämpfung der Möhrenfliege. Arb. physiol. angew. Ent. Berl. 7: 209-232, 269-285.

McClanahan, R. J. and H. D. Niemczyk. 1963. Continuous rearing of the carrot rust fly (Psila rosae Fab.). Can. Ent. 95: 827-830.

Naton, E. 1966. Voraussetzungen für eine Laborzucht der echten Möhrenfliege. Anz. Schädlingsk. 39: 85-89.

1968. Ueber den Einfluss verschiedener Lichtfarben und zweier Populationsdichten auf die Lebensdauer und die Eiproduktion der Echten Möhrenfliege Psila rosae F. Anz. Schädlingsk. 41: 113-116.

Norris, K. R. 1957. A method of marking Calliphoridae (Diptera) during emergence from the puparium. Nature, Lond. 180: 1002.

Peleg, B. A. and R. H. Rhode. 1967. New methods in mass rearing of the mediterranean fruit fly in Costa Rica. J. econ. Ent. 60: 1460-1461.

Petherbridge, F. R., D. W. Wright, and P. G. Davies. 1942. Investigations on the biology and control of the carrot fly (Psila rosae F.). Ann. appl. Biol. 29: 380-392.

Schnitzler, W. H. 1969. Zur Verbesserung der Massenzucht der Kohlfliegen Phorbia brassicae Bouché, Ph. floralis Fallen durch Konservierung der Larvennahrung. Anz. Schädlingsk. 42: 67-71.

Städler, E. 1970. Beitrag zur Kenntnis der Diapause bei der Möhrenfliege (Psila rosae Fabr., Diptera: Psilidae). Mitt. schweiz. ent. Ges. 43: 17-37.

Swailes, G. E. 1967. A substrate for oviposition by the cabbage maggot in laboratory cultures. J. econ. Ent. 60: 619-620.

Wakerley, S. B. 1964 . The sensory behaviour of the carrot fly (Psila rosae Fab., Dipt. Psilidae). Ent. exp. appl. 7: 167-178.

Watkins, T. C. and F. D. Miner. 1943. Flight habit of carrot rust flies suggest possible method of control. J. econ. Ent. 36: 586-588.

Zwölfer, W. 1932. Methoden zur Regulierung von Temperatur und Luftfeuchtigkeit. $Z$. angew. Ent. 19: 497-513.

(Received 7 August 1970) 